\title{
Peningkatan SDM UMKM Melalui Pengayaan Packaging Produk di Kecamatan Jombang Kota Cilegon
}

\author{
Arum Wahyuni Purbohastuti*1, Farah Putri Wenang Lusianingrum², Asmi Ayuning Hidayah³, \\ Didik Aribowo ${ }^{4}$, Desmira $^{5}$ \\ 1,2,3Fakultas Ekonomi dan Bisnis, Universitas Sultan Ageng Tirtayasa \\ 4,5Fakultas Keguruan dan Ilmu Pendidikan, Universitas Sultan Ageng Tirtayasa \\ *e-mail: arum_wp@untirta.ac.id ${ }^{1}$, farahputriwenang@untirta.ac.id ${ }^{2}$, asmiayu20@gmail.com ${ }^{3}$, \\ d_aribowo@untirta.ac.id ${ }^{4}$,desmira@untirta.ac.id ${ }^{5}$
}

\begin{abstract}
The number of Micro, Small and Medium Enterprises (MSMEs) in the city of Cilegon has decreased significantly from 2016 to 2019 amounting to 34,870. The micro and small businesses that are assisted by Posyantek Al-Ikhlas still have problems in developing their product management. On average, MSME actors do not yet master the knowledge of packaging. From these problems, it is necessary to enrich skills regarding packaging with methods training accompanied by mentoring. This training and mentoring program is expected to improve the skills of MSME players in packaging so that they can add value to products and can compete in modern markets. This program will be implemented in four stages including (1) socialization, (2) preparation, (3) implementation of activities, and (4) monitoring and evaluation.
\end{abstract}

Keywords: Mentoring, Human Resource Skills, Packaging, Posyantek Al-Ikhlas.

\section{Abstrak}

Jumlah Usaha Mikro Kecil dan Menengah (UMKM) kota Cilegon mengalami penurunan yang signifikan dari tahun 2016 sampai 2019 sebesar 34.870. Usaha mikro dan kecil binaan dari Posyantek AlIkhlas ini masih memiliki permasalahan dalam pengembangan manajemen produknya. Pelaku UMKM ratarata belum menguasai ilmu mengenai packaging. Dari permasalahan tersebut perlu diadakan pengayaan skill tentang packaging dengan metode pelatihan disertai dengan mentoring, Program pelatihan dan mentoring ini diharapkan dapat meningkatkan skill SDM pelaku UMKM dalam packaging sehingga dapat menambah nilai produk dan dapat bersaing di pasar modern. Program ini akan dilaksanakan dalam empat tahapan meliputi (1) sosialisasi, (2) persiapan, (3) pelaksanaan kegiatan, dan (4) monitoring dan evaluasi

Kata kunci: Pendampingan, Skill SDM, Packaging, Posyantek Al-Ikhlas.

\section{PENDAHULUAN}

\subsection{Aspek Produksi dan Manajemen Usaha Mitra}

Pos Pelayanan Teknologi Tepat Guna (Posyantek) Al-Ikhlas didirikan dengan maksud untuk mempercepat pemanfaatan teknologi tepat guna masyarakaat khususnya pelaku Usaha Mikro, Kecil, dan Menengah (UMKM) di kecamatan Jombang, kota Cilegon. Pendirian Posyantek Al-Ikhlas dilatarbelakangi adanya potensi sumber daya alam lokal yang sangat melimpah. Namun, sumber daya alam lokal tersebut masih belum dikelola atau diinovasi dengan baik oleh pelaku UMKM. Kondisi ini mengakibatkan produk yang dihasilkan oleh pelaku UMKM di kecamatan Jombang nilai jualnya masih rendah dan belum mampu memenuhi standar untuk bersaing di pasar modern. Dengan demikian Posyantek Al-Ikhlas berperan untuk melakukan pembinaan pada pelaku UMKM yang ada di kecamatan Jombang Kota Cilegon Propinsi Banten dalam pemanfaatan teknologi tepat guna untuk meningkatkan kualitas produk.

Salah satu upaya yang dapat dilakukan untuk meningkatkan kualitas produk dengan pembinaan kemampuan manajemen produk bagi pelaku UMKM. Manajemen produk mencakup kegiatan pengembangan produk dan pemasaran produk. Kegiatan pengembangan produk merupakan kegiatan yang fokus pada kondisi internal produk. Sementara, pemasaran produk berfokus pada pelanggan dan kompetisi pasar. Program pengabdian masyarakat ini lebih menitikberatkan pada pengembangan produk internal, seperti mendesain kemasan (packaging) agar nilai jual produk meningkat. 
Menurut Kotler dan Amstrong (2012) packaging (kemasan) merupakan suatu bentuk kegiatan yang melibatkan desain serta produk, sehingga kemasan ini dapat berfungsi untuk melindungi produk di dalamnya. Fungsi kemasan dalam hal ini berhubungan dengan proteksi produk atau keamanan produk. Karakteristik produk, perbedaan iklim, prasarana transportasi, dan saluran distribusi berdampak pada pemilihan desain dan jenis pengemasan. Selain itu, preferensi konsumen menyangkut warna, ukuran, dan penampilan produk juga perlu dipertimbangkan dalam mendesain kemasan produk (Simamora, 2017). Hal ini disebabkan pengemasan produk yang menarik dan berstandar akan mempermudah untuk kegiatan promosi.

Posyantek Al-Ikhlas memegang peranan kunci sebagai pembina dan motivator bagi pelaku UMKM untuk mengembangkan desain kemasan. Namun, Posyantek Al-Ikhlas membutuhkan mitra pendamping untuk memberikan pengayaan skill tentang packaging agar produk UMKM mitra binaan Posyantek Al-Ikhlas mampu bersaing. Kondisi ini disebabkan pembinaan yang selama ini telah dilakukan oleh Posyantek Al-Ikhlas belum menunjukkan hasil yang maksimal. Dengan demikian diharapkan pihak Perguruan Tinggi khususnya bidang ekonomi manajemen mampu memberikan pendampingan dengan metode coaching manajemen produk padaUMKM mitra binaan Posyantek Al-Ikhlas. Hal ini tentunya memerlukan kerjasama antara pihak Perguruan tinggi dengan Posyantek Al-Ikhlas.

\subsection{Persoalan yang Dihadapi Mitra}

Posyantek Al-Ikhlas memiliki mitra binaan UMKM yang bergerak dalam bidang kuliner, kerajinan tangan, dan fashion. Mitra UMKM binaan Posyantek Al-Ikhlas mayoritas memiliki masalah mengenai manajemen produk yakni packaging. Permasalahan yang dihadapi UMKM ini tentunya disrespon oleh Posyantek Al-Ikhlas dengan melakukan pembinaan manajemen produk. Posyantek Al-Ikhlas selama ini berusaha menciptakan program pendampingan UMKM yang berkesinambungan agar ketahanan pangan pada masyarakat UMKM tetap terjaga. Namun, sumber daya manusia (SDM) Posyantek Al-Ikhlas masih terbatas keilmuwannya baik secara teoritis maupun praktik. Terlebih lagi SDM yang menguasai bidang ilmu ekonomi manajemen yang tentunya diharapkan dapat memberikan pembinaan dan pendampingan tentang pengembangan produk bagi pelaku UMKM. Dengan demikian, Posyantek membutuhkan kerjasama dengan pihak perguruan tinggi untuk pengelolaan program pembinaan dan pendampingan UMKM secara konsisten dan berkelanjutan.

Selanjutnya, berdasarkan pra survey di lapangan dan hasil diskusi dengan Posyantek AlIkhlas, maka dapat dirumuskan masalah prioritas yang perlu ditangani oleh Posyantek Al-Ihklas dengan pendamping dari perguruan tinggi yaitu:

1. Produk UMKM yang masih sangat sederhana.

2. Pengemasan produk UMKM masih terkesan sangat tradisional.

3. Material yang digunakan untuk pengemasan produk kurang mempertimbangkan sifat produknya.

\subsection{Tujuan Kegiatan}

Meningkatkan skill SDM pelaku UMKM binaan Posyantek Al-Ikhlas dalam hal bagaimana cara membuat kemasan produk agar menambah nilai jual.

\subsection{Bentuk Kegiatan}

Kegiatan pengabdian ini berbentuk pendampingan dengan pelatihan pembuatan kemasan yang menarik dan sesuai standar untuk memberikan nilai tambah pada produk UMKM binaan Posyantek Al-Ikhlas kecamatan Jombang Kota Cilegon Propinsi Banten. 


\section{METODE}

Pada bagian metode, pemecahan permasalahan untuk meningkatkan skill SDM pelaku UMKM mitra binaan Posyantek Al-Ikhlas kecamatan Jombang Kota Cilegon Propinsi Banten dapat dilakukan dengan berkolaborasi dengan perguruan tinggi. Selanjutnya, kegiatan pengabdian masyarakat dilakukan dengan cara pendampingan disertai dengan pelatihan yang dapat diimplementasikan dalam empat tahapan antara lain (1) sosialisasi, (2) persiapan , (3) pelaksanaan kegiatan, dan (4) monitoring dan evaluasi.

Tabel 1 Jenis Kegiatan, Partisipasi Mitra, Luaran Kegiatan dan Solusi Masalah

\begin{tabular}{|c|c|c|c|c|}
\hline No & Jenis Kegiatan & Partisipasi Mitra & Luaran Kegiatan & Solusi masalah \\
\hline 1. & Sosialisasi PPM & $\begin{array}{l}\text { Pihak dari perguruan tinggi } \\
\text { memberikan jadwal } \\
\text { kegiatan pada Posyantek } \\
\text { kemudian disosialisasikan } \\
\text { pada mitra binaan }\end{array}$ & $\begin{array}{l}\text { UMKM mitra } \\
\text { binaan } \\
\text { mengetahui } \\
\text { Waktu } \\
\text { pelaksanaan } \\
\text { PPM }\end{array}$ & $\begin{array}{l}\text { Menggunakan } \\
\text { media } \\
\text { komunikasi } \\
\text { online dan } \\
\text { offline }\end{array}$ \\
\hline 2. & Persiapan & $\begin{array}{l}\text { Pihak Posyantek } \\
\text { menyiapkan tempat dan } \\
\text { alat-alat untuk } \\
\text { pendampingan dan } \\
\text { pelatihan }\end{array}$ & $\begin{array}{l}\text { SDM UMKM } \\
\text { menyiapkan } \\
\text { produk untuk } \\
\text { dibawa } \\
\text { dikegiatan } \\
\text { pelatihan }\end{array}$ & $\begin{array}{l}\text { Menyiapkan hal- } \\
\text { hal yang } \\
\text { dibutuhkan pada } \\
\text { saat kegiatan }\end{array}$ \\
\hline 3. & $\begin{array}{l}\text { Pelaksanaan } \\
\text { Kegiatan }\end{array}$ & $\begin{array}{l}\text { Pihak Posyantek dan } \\
\text { perguruan tinggi } \\
\text { mendampingi pada saat } \\
\text { pendampingan disertai } \\
\text { dengan pelatihan packaging }\end{array}$ & $\begin{array}{l}\text { SDM UMKM } \\
\text { mampu membuat } \\
\text { kemasan yang } \\
\text { menarik pada } \\
\text { produk }\end{array}$ & $\begin{array}{l}\text { Pendampingan } \\
\text { dan pelatihan }\end{array}$ \\
\hline 4. & $\begin{array}{l}\text { Monitoring dan } \\
\text { Evaluasi } \\
\text { (Monev) }\end{array}$ & $\begin{array}{l}\text { Monitoring dan evaluasi } \\
\text { bersama tim PPM }\end{array}$ & $\begin{array}{l}\text { Melakukan } \\
\text { monev }\end{array}$ & $\begin{array}{l}\text { Dilakukan } \\
\text { pendampingan } \\
\text { terhadap tim } \\
\text { monev dari } \\
\text { UMKM mitra } \\
\text { binaan }\end{array}$ \\
\hline
\end{tabular}

\section{HASIL DAN PEMBAHASAN}

Kemasan yang dilakukan pada kegiatan pengabdian pada masyarakat bersama mitra UMKM Posyantek Al-Ikhlas Kecamatan Jombang Kota Cilegon Propinsi Banten dirancang dengan baik yang bertujuan dapat membangun ekuitas merek dan mendorong penjualan pada mitra UMKM binaan Posyantek Al-Ikhlas. Kemasan produk makanan ternyata tak bisa dianggap sepele dalam sebuah bisnis. Karena kemasan selain berfungsi mempercantik suatu produk sehingga meningkatkan nilai jual. Ternyata plastik juga mampu mempengaruhi daya simpan atau kadaluwarsa suatu produk. Sehingga tidak boleh sembarangan memilih bahan untuk kemasan suatu produk. Karena jika salah maka produk yang dikemas akan cepat rusak dan membuat pembeli tidak berminat kembali terhadap produk kita.

Bahan yang dipergunakan untuk membuat kemasan akan sangat berpengaruh terhadap desain dan bentuk kemasan yang akan dibuat sekaligus berpengaruh terhadap kemasan produk yang dikemas, misalnya: suatu produk yang berupa cairan tidak akan aman atau dapat dikemas dalam bentuk kertas, produk-produk yang tidak tahan terhadap sinar ultra violet, tidak akan baik bila dikemas dalam plastik atau kaca transparan. Kegiatan pengabdian pada masyarakat dengan 
mengambil tema terkait bagaimana pola pengemasan sebuah produk makanan di awali dengan penyampaian materi berupa informasi terkait seputar kemasan produk-produk olahan makanan.

Kegiatan yang dihadiri oleh seluruh mitra UMKM (usaha mikro kecil dan menengah) binaan Posyantek Al-Ikhlas se-Kecematan Jombang Kota Cilegon Propinsi Banten bertempat di Aula Kecamatan Jombang Kota Cilegon Propinsi Banten. Acara yang digagas oleh Fakultas Ekonomi dan Bisnis Universitas Sultan Ageng Tirtayasa merupakan wujud dari Tri Dharma Perguruan Tinggi dihadiri pula oleh instansi lain yang terkait seperti unsur pemerintah daerah yang diwakili oleh Sub Bidang Teknologi Tepat Guna Dinas Sosial Kota Cilegon serta dari pihak Kecamatan Jombang di wakili oleh Sekretaris Kecamatan Jombang Kota Cilegon kemudian dari pihak Posyantek Al-Ikhlas yang dihadiri oleh Ketua Posyantek Al-Ikhlas.

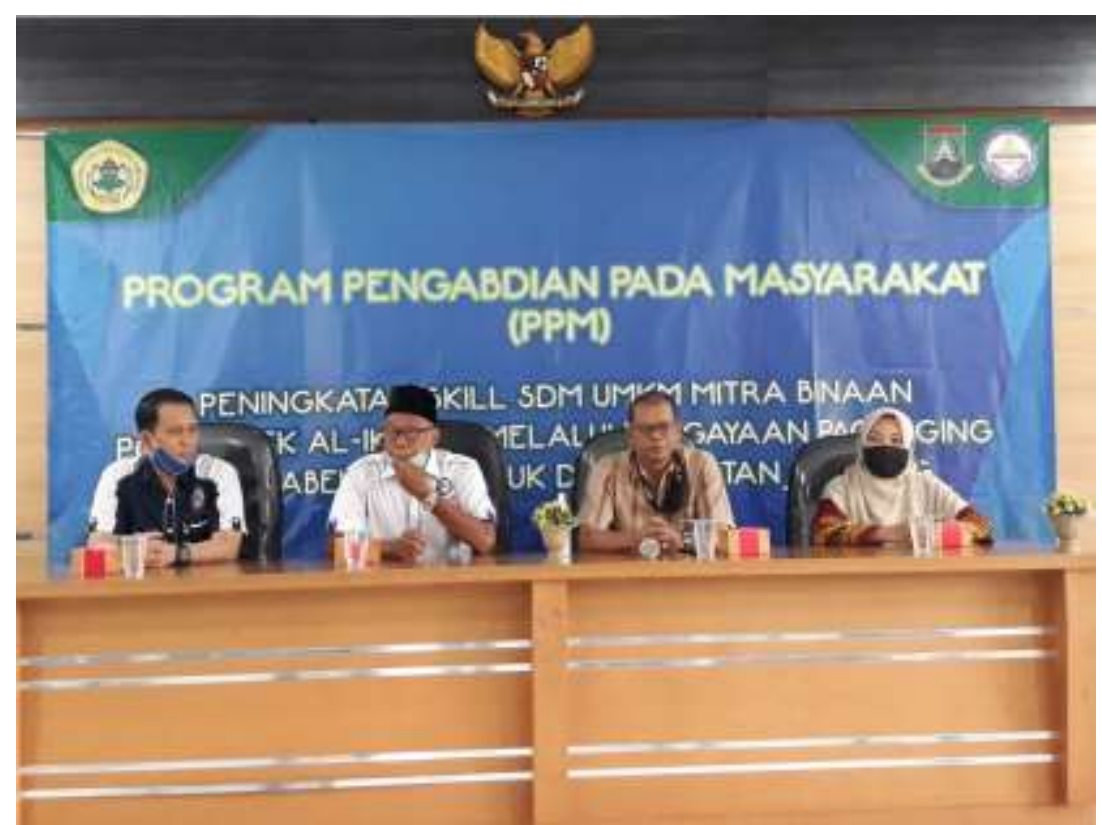

Gambar 1. Kegiatan Pengabdian Pada Masyarakat di Aula Kecamatan Jombang Kota Cilegon Propinsi Banten

Menindaklanjuti terkait materi yang disampaikan kepada mitra binaan UMKM Posyantek Al-Ikhlas yakni terkait dengan pengemasan suatu produk olahan bahan makanan yang telah dilakukan oleh mitra binaan UMKM Posyantek Al-Ikhlas. Kemasan (packaging) merupakan bagian pertama produk yang dihadapi pembeli dan mampu menarik atau menyingkirkan pembeli. Pengemasan suatu produk biasanya dilakukan oleh produsen untuk dapat merebut minat konsumen terhadap pembelian produk. 


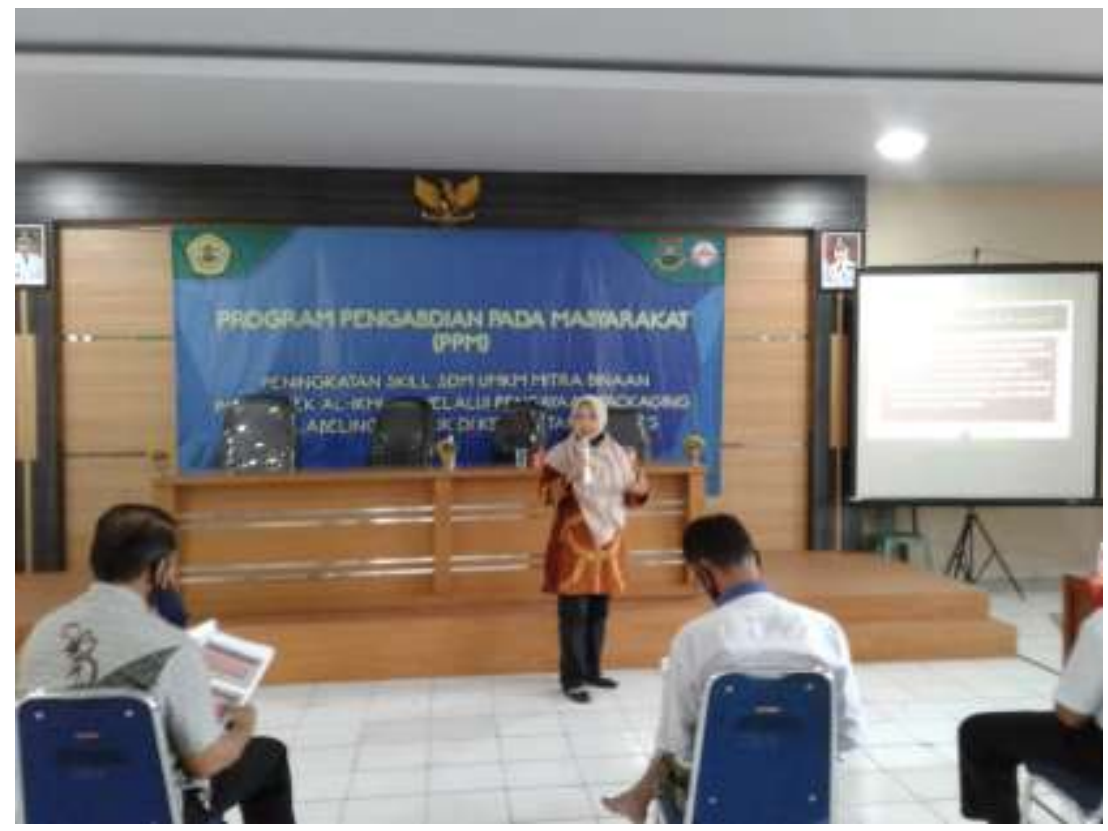

Gambar 2. Penyampaian Materi Tentang Kemasan Produk Olahan Makanan bersama Mitra Binaan UMKM Posyantek Al-Ikhlas Kecamatan Jombang Kota Cilegon

Dalam materi pengemasan ini, produsen berusaha memberikan kesan yang baik pada kemasan produknya dan menciptakan model kemasan baru yang berbeda dengan produsen lain yang memproduksi produk-produk sejenis dalam pasar yang sama. Berdasarkan struktur isi, kemasan dibagi menjadi tiga jenis yakni:

a. Kemasan primer, yakni bahan kemas langsung dari bahan pangan seperti kemasan makanan berbahan plastik, botol minuman berbahan plastik, dan lain sebagainya.

b. Kemasan sekunder, yakni kemasan yang fungsi utamanya melindungi kelompok kemasan lainnya, seperti misalnya kotak karton untuk wadah makanan ringan, kotak kayu untuk wadah buah-buahan yang dibungkus dan sebagainya.

c. Kemasan tersier dan kuarter yakni kemasan yang diperlukan untuk menyimpan, pengiriman atau identifikasi, kemasan tersier umumnya digunakan sebagai pelindung selama pengangkutan.

Berdasarkan frekuensi pemakainnya, kemasan dibagi menjadi tiga jenis yakni:

a. Kemasan sekali pakai "Disposable”, yakni kemasan yang langsung dibuang setelah satu kali pakai. Contohnya bungkus plastik, bungkus permen, bungkus daun, karton dus dan makanan kaleng.

b. Kemasan yang dapat dipakai berulang kali "multi-trip", yakni kemasan jenis ini umumnya tidak dibuang oleh konsumen, akan tetapi dikembalikan lagi pada agen penjual untuk kemudian dimanfaatkan ulang oleh pabrik. Contohnya botol minuman dan botol kecap.

c. Kemasan yang tidak dibuang "semi disposable", yakni kemasan ini biasanya digunakan untuk kepentingan lain dirumah konsumen setelah dipakai. Contohnya kaleng biskuit, kaleng susu dan berbagai jenis botol.

Berdasarkan tingkat kesiapan pakai, kemasan dibagi menjadi dua jenis yakni:

a. Kemasan siap pakai, yakni bahan kemas yang siap untuk diisi dengan bentuk yang telah sempurna sejak keluar dari pabrik. Contohnya ialah wadah botol, wadah kaleng dan sebagainya.

b. Kemasan siap dirakit, yakni kemasan yang masih memerlukan tahap perakitan sebelum pengisian misalnya kaleng dalam bentuk lempengan dan silinder fleksibel, wadah yang terbuat dari kertas, foil atau plastik. 


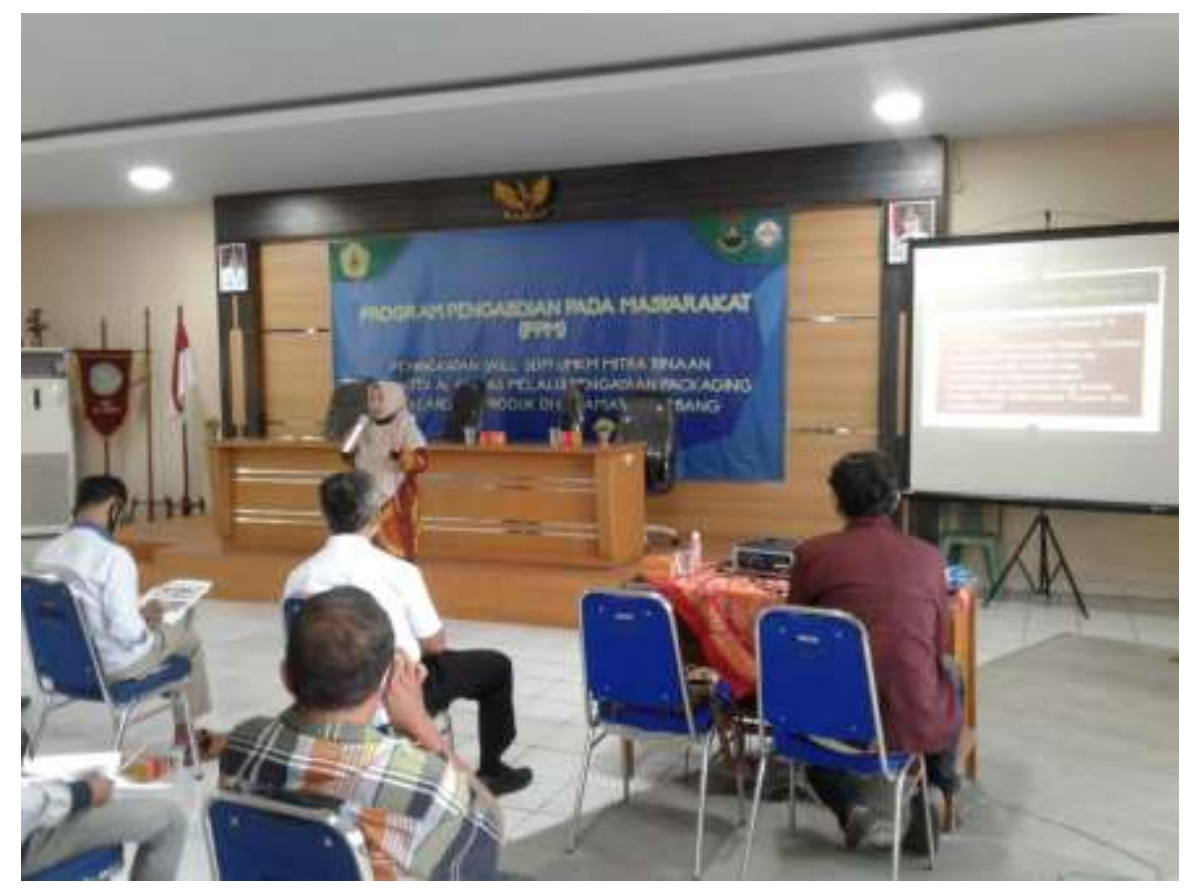

Gambar 3. Penyampaian materi tentang pemilihan kemasan dan daya tarik kemasan dari UMKM mitra binaan Posyantek Al-Ikhlas Kecamatan Jombang

Daya tarik kemasan sangat penting guna tertangkapnya stimulus oleh konsumen yang di sampaikan ke produsen sehingga diharapkan konsumen tertarik pada produk tersebut. Menurut Wiryo (1999:10) daya tarik visual kemasan dapat digolongkan menjadi dua yaitu: daya tarik visual dan daya tarik praktis. Daya tarik visual mengacu pada penampilan kemasan atau lebel suatuproduk mencakup warna, bentuk, merk, ilustrasi, teks, tata letak (Wirya, 1999:28-30). Daya tarik praktis ini merupakan efektifitas efesiensi suatu kemasan yang ditujukan kepada konsumen maupun distributor atau pengecer.

Materi yang selanjutnya yang tidak kalah pentingnya adalah mempraktikan bagaimana melakukan pengemasan sebuah produk dengan menggunakan kemasan berbahan plastik yang dibantu dengan sentuhan teknologi tepat guna berupa alat press plastik yakni hand sealer. Mesin hand sealer adalah mesin kemasan untuk menyegel plastik agar isi kemasan menjadi lebih aman dan higienis. Mesin kemasan ini terdiri dari banyak ukuran yang bisa disesuaikan dengan kebutuhan. Penggunaan hand sealer sangat cocok digunakan bagi mitra binaan Posyantek AlIkhlas yang memiliki bisnis Usaha Mikro, Kecil, dan Menengah (UMKM). Dibandingkan dengan mesin perekat umumnya seperti Vacuum Sealer, sistem kerjanya, yaitu memanfaatkan pemanas elektrik instan. Pemanas elektrik ini akan melelehkan plastik dan menjadikannya menempel. Alat tersebut biasanya digunakan untuk berbagai kebutuhan rumah tangga. Seringkali juga digunakan untuk keperluan industri rumahan. Misalnya saja digunakan untuk mengemas berbagai jenis produk sepeti makanan ringan. Penggunaan hand sealer sebagai metode pengemasan sederhana memang bisa dibilang banyak untungnya bagi industri kecil dan rumahan. Hand sealer merupakan salah satu mesin kemasan modern dengan bandrol yang bisa dibilang paling terjangkau jika dibandingkan dengan mesin sejenis. 


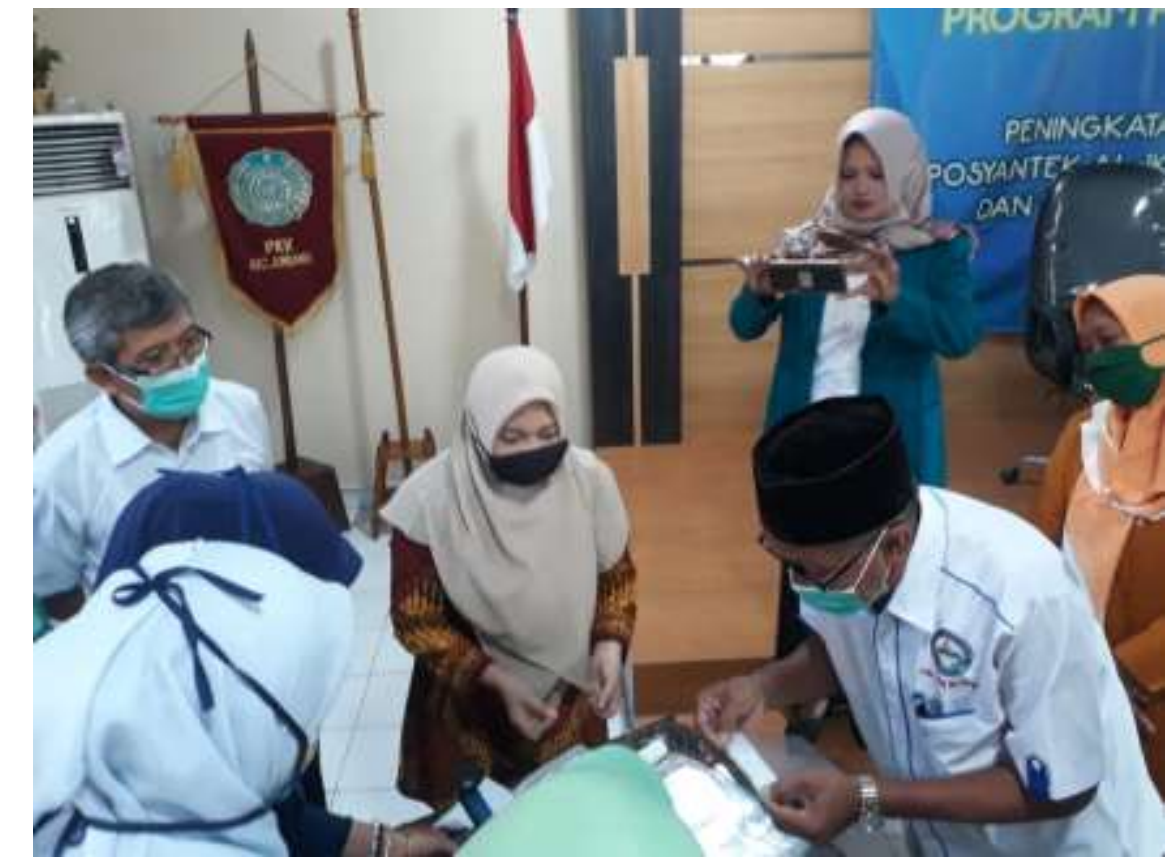

Gambar 4. Peserta kegiatan antusias dalam mengikuti praktik menggunakan Hand Sealer bersama Mitra Binaan UMKM Posyantek Al-Ikhlas Kecamatan Jombang Kota Cilegon

Sebagai produk yang membantu dan memudahkan pengemasan, mesin hand sealer ini memiliki banyak keunggulan. Produk ini ukurannya kecil, sehingga mudah digunakan oleh siapa pun. Selain itu alat press tangan ini termasuk alat yang user friendly. Jadi setiap orang bisa memahami cara penggunaannya dan dengan mudah menggunakan alat press. Semua itu dilakukan tanpa harus membuka manual book atau panduan terlebih dahulu. Keunggulan lainnya, alat press tangan tersebut bisa digunakan untuk merekatkan plastik makanan yang sudah dibuka di rumah. Selain itu, juga merekatkan berbagai makanan yang belum habis, sehingga makanan tersebut bisa lebih tahan lama tanpa harus menyimpannya di toples. Produk ini bisa juga digunakan untuk membungkus berbagai kemasan plastik industri rumahan yang berukuran kecil. Misalnya saja mitra UMKM memiliki produk makanan ringan, atau produk bumbu masakan. Produk yang dikemas dan dijual dalam bentuk kemasan kecil plastik, bisa menggunakan mesin press plastik untuk proses merekatkan kemasan produk.

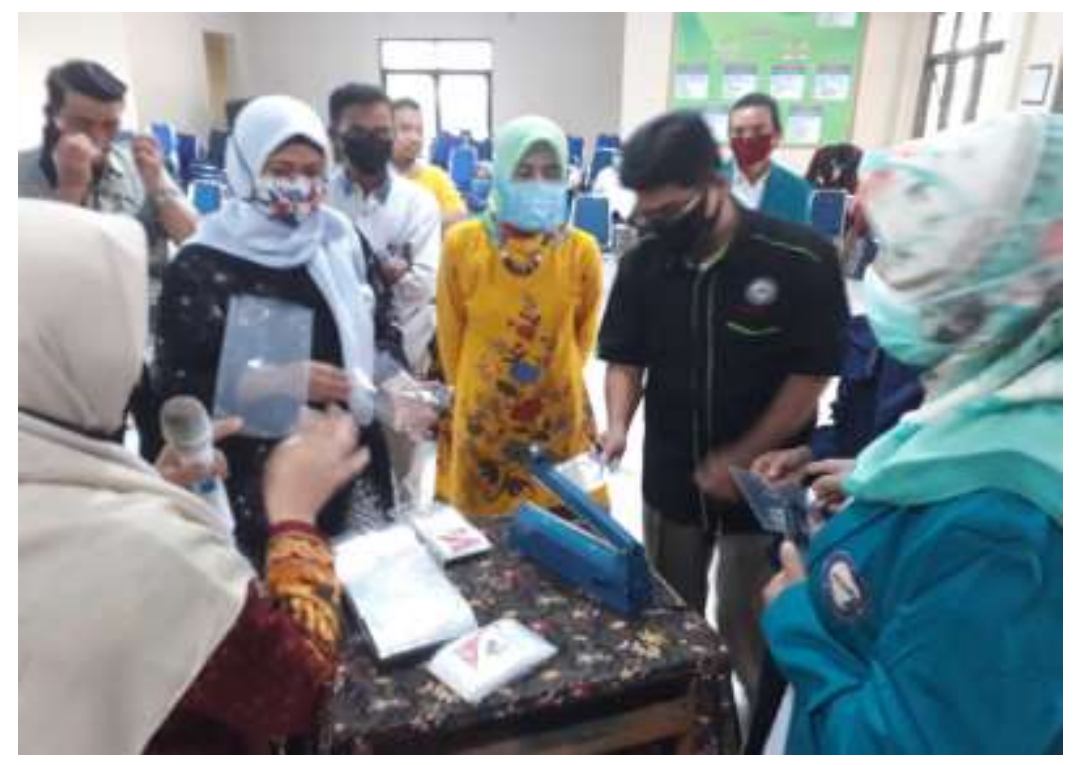

Gambar 5. Peserta Mitra UMKM mencoba mempraktikan press kemasan plastik ukuran kecil menggunakan Hand Sealer 
Antusiasme peserta kegiatan praktik menggunakan Hand Sealer untuk produk kemasan mitra UMKM Binaan Posyantek Al-Ikhlas Kecamatan Jombang Kota Cilegon sangat tinggi mengikuti materi kegiatan pengabdian pada masyarakat yang diinisiasi oleh Fakultas Ekonomi dan Bisnis Universitas Sultan Ageng Tirtayasa (Untirta).

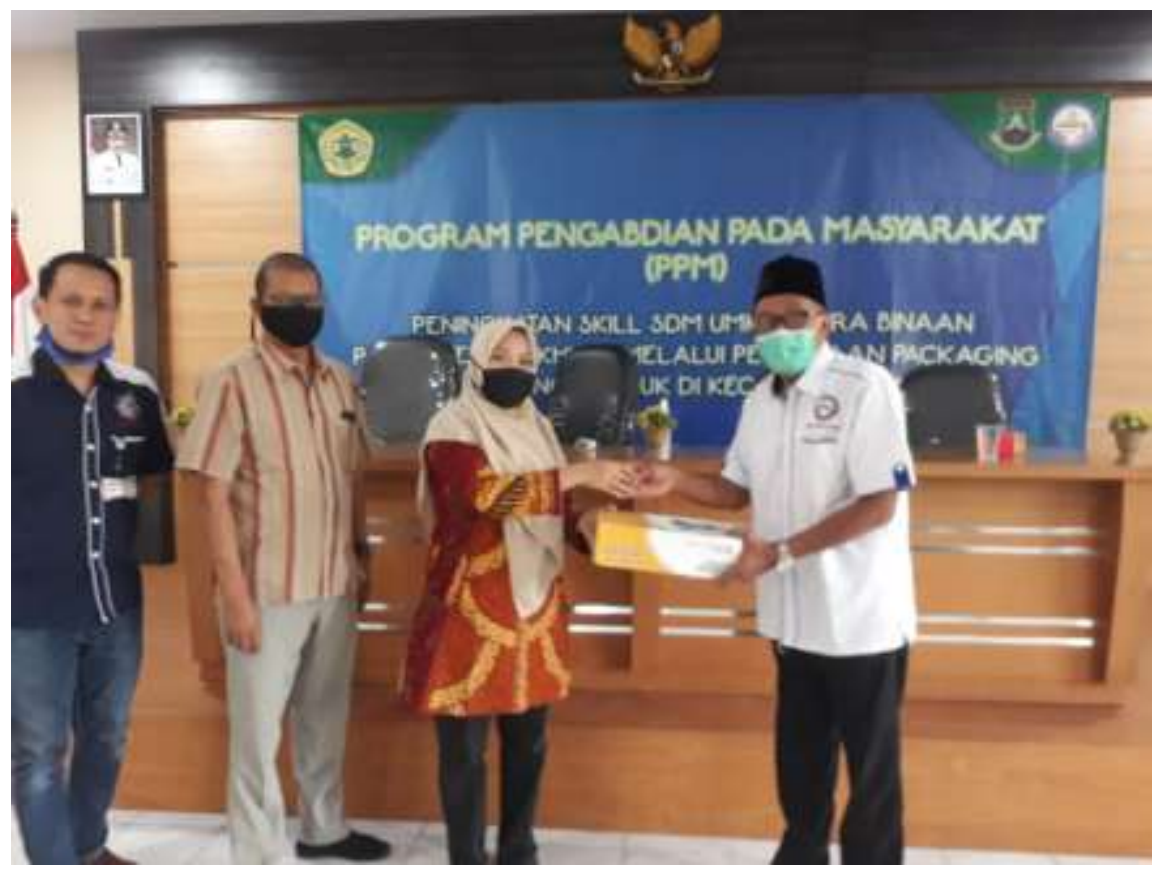

Gambar 6. Penyerahan bantuan alat teknologi tepat guna berupa Hand Sealer kepada Posyantek Al-Ikhlas Kecamatan Jombang untuk diteruskan kepada mitra Binaan UMKM

Dipenghujung kegiatan, dari pihak Untirta melakukan serah terima alat Hand Sealer kepada peserta kegiatan yakni mitra UMKM binaan Posyantek Al-Ikhlas untuk dapat dipergunakan membantu usaha pengemasan sekaligus meningkatkan kualitas produk unggulan UMKM khususnya dalam olahan makanan.

\section{KESIMPULAN}

Kegiatan pengabdian pada masyarakat (PPM) yang digagas oleh UNiversitas Sultan Ageng Tirtayasa (Untirta) bersama Posyantek Al-Ikhlas Kecamatan Jombang Kota Cilegon dapat diambil kesimpulan sebagai berikut :

1. Kegiatan berupa pelatihan kemasan produk berjalan sangat baik dan mendapatkan respon positif dari mitra dan sekaligus terbantu dalam hal peningkatan pengetahuan dan wawasan mengenai kemasan produk untuk pelaku UMKM mitra Binaan Posyantek AlIkhlas Kecamatan Jombang Kota Cilegon

2. Alat teknologi tepat guna berupa Hand Sealer yang digunakan dalam pelaihan kemasan produk ini sangat bermanfaat dan dapat membantu melakukan pengemasan yang lebih baik dari sebelumnya bagi pelaku UMKM mita binaan Posyantek Al-Ikhlas Kecamatan Jombang Kota Cilegon.

\section{UCAPAN TERIMA KASIH}

Penulis mengucapkan terima kasih kepada Universitas Sultan Ageng Tirtayasa khususnya Fakultas Ekonomi dan Bisnis serta Mitra Binaan UMKM yang dikelola oleh Posyantek Al-Ikhlas 
Kecamatan Jombang Kota Cilegon yang telah memberi dukungan moril dan pembiayaan terhadap keberlangsungan pengabdian ini yang mendapat respon menggembirakan bagi peserta kegiatan.

\section{DAFTAR PUSTAKA}

Angeline, Mia. 2010. Cara Desain Kemasan Produk Mempengaruhi Respons Motif Kognitif Dan Perilaku Konsumen. Jurnal Humaniora.Vol.1 No.2.

Asyhari, dkk. 2018. Pengembangan produk nutrasetika berbasis sayuran organik bagi petani sayuran organik. Unnisula.

Damayanti, C. 2015. Packaging The Brand. Modul pelatihan. Rumah Kemasan Bandung.

Kotler, Philip. 2000. Marketing Management. Edisi Milenium. Prentice Hall Intl Inc New Jersey.

Kotler, Philip, and Gary Armstrong. 2012. Prinsip-prinsip pemasaran. Edisi 13. Jilid 1. Jakarta : Erlangga.

Nelvia I, dkk. 2017. Pembekalan Wirausaha Mandiri Bagi UMKM Makanan Tradisional. Fakultas Ekonomi UNAND.

Simamora, Bilson. 2007. Panduan Riset dan Perilaku Konsumen. Jakarta: Gramedia

Syahputri, ria. 2015. Pengaruh kemasan, merek dan harga terhadap loyalitas pada ukm kripik singkong sulis di samarinda. E-journal ilmi administrasi bisnis.

http://kecjombang.cilegon.go.id/index.php/web/data/posyantek. 